\title{
IMMUNOLOGICAL MARKERS AND HEMATOLOGICAL PARAMETERS AMONG NEWLY DIAGNOSED TUBERCULOSIS PATIENTS AT JIMMA UNIVERSITY SPECIALIZED HOSPITAL
}

\author{
Dereje Atomsa $^{1}$, Gemeda Abebe ${ }^{1}$, Tsegaye Sewunet ${ }^{1}$
}

\begin{abstract}
BACKGROUND: Tuberculosis (TB) is a cause of 1.2-1.5 million deaths worldwide, including deaths from TB among HIV positive people. Determining the extent of immune cells belonging to cell mediated immunity and haematological parameters is critical to maximize the potential benefit of anti-tubercular treatment and case management.

MATERIALS AND METHODS: Comparative cross sectional study was conducted to determine the white blood cell (WBC) count, $\mathrm{CD}_{4}, \mathrm{CD}_{8}$, haemoglobin (Hgb), red blood cell (RBC) count, mean corpuscular haemoglobin (MCHC), mean corpuscular volume (MCV) between newly diagnosed TB patients and apparently healthy controls $(\mathrm{HCs})$.

RESULTS: From consecutively enrolled $108 \mathrm{~TB}$ patients, pulmonary TB (PTB) accounted for 48(44.4\%), TB lymphadenitis accounted for 48(44.4\%), and disseminated/miliary TB accounted for 12(11.1\%). Analysis of variance revealed that mean $\pm S D$ of $\mathrm{CD}_{4}$ count of male TB patients $(650 \pm$ 224 cells/ul) was significantly lower than male control group $(883 \pm 256 \mathrm{cells} / \mu \mathrm{l})(p=0.001)$. In a similar manner, the mean $\mathrm{CD}_{4}$ count of female $\mathrm{TB}$ patients $(793 \pm 332 \mathrm{cell} / \mathrm{sl})$ was lower than female control group $(975 \pm 300$ cells $/ \mu l)(p=0.001)$. There was no statistically significant difference in $C D_{8}$ counts between cases and controls for both genders. Forty (37.0\%) TB patients had developed anaemia of whom 22(55\%) were among PTB, 13(32.5\%) from tuberculous lymphadenitis and 5(20\%) from disseminated TB. Morphologically, from all anaemia among TB patients, normocytic normochromic anaemia accounted for 15(37.5\%) followed by normocytic hypochromic anaemia 13(30.4\%).

CONCLUSION: $\mathrm{CD}_{4}$ lymphopenia was significant among TB patients. Granulocyte count was increased. Mild anaemia was found major haematological abnormality among newly diagnosed TB patients.

KEYWORDS: Tuberculosis, $\mathrm{CD}_{4}$ count, $C D_{8}$ count, anaemia, haemoglobin
\end{abstract}

DOI: http://dx.doi.org/10.4314/ejhs.v24i4.6

\section{INTRODUCTION}

TB was declared a global emergency in 1993. In that year an estimated 7-8 million cases and 1.31.6 million deaths occurred (1). Despite the availability of effective treatment, TB remains a major global health problem. After about a decade in 2010, there were an estimated 8.5-9.2 million cases and 1.22-1.59 million deaths including deaths from Human Immunodeficiency Virus (HIV)-associated TB (2). Hospital data of the
Ministry of health in Ethiopia show that TB is the leading cause of morbidity, the third cause of hospital admission, and the first cause of hospital death in Ethiopia (3). According to WHO Global Report of 2011, Ethiopia ranked 7th among the high TB burden countries in the world, with an estimated incidence of all forms of TB of 261/100,000 population/year. The estimated prevalence of all forms of $\mathrm{TB}$ reported was 394/100,000 population (2).

${ }^{1}$ Department of Medical Laboratory Science and Pathology, Jimma University, Ethiopia Corresponding Author: Tsegaye Sewunet, Email: tsegaye.sewunet@ju.edu.et 
M. tuberculosis targets macrophages which are important effector cells in the immune system, as its preferred habitat. Whereas resting macrophages fail to harm M. tuberculosis, activated macrophages can control the growth of the microbe, although sterile eradication is seldom achieved. Several different T-cell populations are required for the successful control of the pathogen. This dynamic interplay underlying protection is the reason for the long-term persistence of $\mathrm{M}$. tuberculosis (4). $\mathrm{CD}_{4}$ lymphocytopenia is a welldefined risk factor for the development of active TB in patients infected with HIV. TB may be also associated with $\mathrm{CD}_{4}$ and $\mathrm{CD}_{8}$ lymphopenia even in patients without HIV virus infection (5).

$\mathrm{CD}_{4} \mathrm{~T}$ cells play central roles in the function of the immune system: They help B cells make antibody, enhance and maintain responses of $\mathrm{CD}_{8}$ $\mathrm{T}$ cells, regulate macrophage function, orchestrate immune responses against a wide variety of pathogenic microorganisms, and regulate/suppress immune responses both to control autoimmunity and to adjust the magnitude and persistence of responses. $\mathrm{CD}_{4} \mathrm{~T}$ cells are important mediators of immunologic memory, and when their numbers are diminished or their functions are lost, the individual becomes susceptible to a wide range of infectious disorders including TB (6).

The protective and pathologic response to $\mathrm{M}$. tuberculosis is complex and multifaceted, involving many components of the immune system. A clear picture of the network of immune responses to this pathogen, as well as an understanding of the effector functions of these components is essential to the design and implementation of effective treatments for TB (7). It is essential to determine immunological and haematological parameters at the baseline of antiTB treatment for further consideration of supportive care and other treatment options that might be required for some patients to enhance the anti-TB treatment outcome.

\section{MATERIALS AND METHODS}

A Comparative cross-sectional study was conducted between TB patients and apparently healthy controls at Jimma University Specialized Hospital TB clinic from January- 2012 to May2012. One hundred eight newly diagnosed TB patients and 116 HIV negative apparently healthy controls in the age group of 15-55 years were included in the study consecutively. The diagnosis of TB was made according to the national guideline. The cases were reportedly naive to antiTB treatment. Newly diagnosed TB patients who have already started anti-TB treatment, receiving any kind of immunosuppressive drugs, known or suspected history of other chronic disease, pregnant women and HIV positive individuals were excluded. Apparently healthy controls were recruited from blood donors $15-55$ years of age.

Data was collected during enrolment using pre-structured questionnaire. Four milliliters of blood specimen was collected in pre-labelled evacuated tubes (BD vacutainer, Oxford, UK) from each study participant. $\mathrm{CD}_{4}, \mathrm{CD}_{8}$ and $\mathrm{CD}_{4} /$ $\mathrm{CD}_{8}$ ratio counts were performed on BD- FACS Count System (Becton Dickinson Biosciences, San Jose California, USA) and CBC was done on Cell-Dyn 1800 system (Abbott Diagnostic, Illinois, USA). Data from the laboratory investigation and questionnaire were compiled and analyzed using SPSS 16.0. Mean values were calculated and compared using one way ANOVA test for TB patients and apparently healthy controls. Significant differences were evaluated between groups by Post Hoc Tukey test. P value < 0.05 was considered statistically significant. The study was approved by the Ethical Review Board of Jimma University, College of Public Health and Medical sciences, Department of Medical Laboratory Science and Pathology. The objective of the study was explained to the patients and all the study subjects (cases and controls) were included after written consent was obtained.

\section{RESULTS}

A total of 108 newly diagnosed TB patients and 116 healthy controls were enrolled in this study. Cases accounted for 45(41.7\%) males and $63(58.3 \%)$ females, and healthy controls account for 54(46.6\%) males and 62(53.4\%) females. There was no statistically significant difference between the mean age $(\mathrm{p}=0.094)$ and sex distribution $(p=0.599)$ of the TB patients and healthy controls. Distribution of age, sex, educational status and body mass index (BMI) among newly diagnosed TB patients is shown in (Table 1). 
Table 1: Distribution of age, sex, educational status, and body mass index among newly diagnosed TB patients

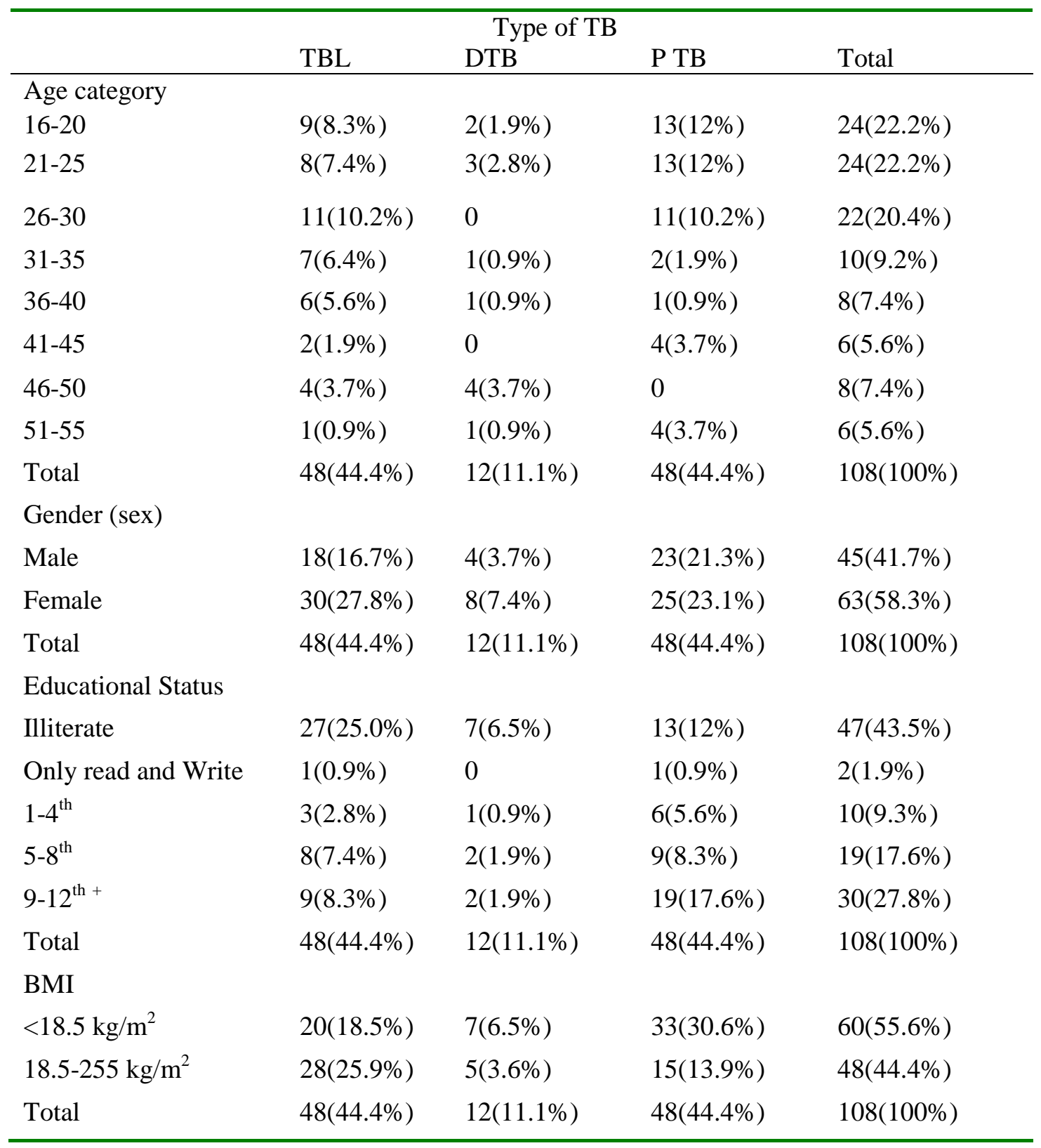

$\mathrm{TBL}=$ tuberculous lymphadenitis, $\mathrm{DTB}=$ disseminated $\mathrm{TB}, \mathrm{PTB}=$ pulmonary $\mathrm{TB}$

From the total of 108 cases, PTB accounts 48(44.4\%), TB lymphadenitis (TBL) 48(44.4\%) and disseminated/miliary TB (DTB) accounts $12(11.1 \%)$ (Table 1). Compared with male healthy controls $\left(6.83 \pm 2.17 \times 10^{3}\right.$ cells $\left./ \mu \mathrm{l}\right)$ male $\mathrm{TB}$ patients had significantly high mean absolute WBC count $\left(8.35 \pm 3.3 \times 10^{3}\right.$ cells $\left./ \mu \mathrm{l}\right) \quad(\mathrm{p}=007)$. Female TB patients also had significantly high mean absolute WBC count (8.62 \pm 2.89 $\left.\mathrm{x} 10^{3} \mathrm{cells} / \mu \mathrm{l}\right)$ than female healthy controls $\left(6.67 \pm 1.5 \times 10^{3} \mathrm{cells} / \mu \mathrm{l}\right) \quad(\mathrm{p}=0.001)$. The mean absolute granulocytes count (AGC) of both male and female TB patients were significantly higher than healthy controls $(\mathrm{p}=0.001)$. Absolute lymphocytes counts of male TB patients were significantly lower compared with male healthy controls $(\mathrm{p}=0.008)$. But, there was no statistically significant difference between female TB patients 
and female healthy controls $(\mathrm{p}=0.101)$ (Table 2). Mean $\mathrm{CD}_{4}$ count of male TB patients $(650 \pm$ 224 cells $/ \mu \mathrm{l})$ were significantly lower than male healthy controls $(883 \pm 256$ cells $/ \mu 1)(\mathrm{p}=001)$. Similarly, the mean $\mathrm{CD}_{4}$ count of female $\mathrm{TB}$ patients $(793 \pm 332$ cells $/ \mu \mathrm{l})$ is lower than the mean
$\mathrm{CD}_{4}$ count of female healthy controls $(975 \pm 300$ cells $/ \mu \mathrm{l})(\mathrm{p}=0.002)$. But, in case of $\mathrm{CD}_{8}$ count, there was no statistically significant difference between cases and controls in both genders (Table 2).

Table 2: Comparison of mean values of immunological and hematological parameters in the newly diagnosed TB patients versus healthy control

\begin{tabular}{|c|c|c|c|c|c|c|}
\hline & \multicolumn{2}{|l|}{ Male } & \multicolumn{3}{|c|}{ Female } & \multirow[b]{2}{*}{ P-value } \\
\hline & $\begin{array}{l}\text { TB patient } \\
\text { mean } \pm \text { SD }\end{array}$ & $\begin{array}{l}\text { HC mean } \\
\pm \mathrm{SD}\end{array}$ & P-value & $\begin{array}{l}\mathrm{TB} \text { patient } \\
\text { mean } \pm \mathrm{SD}\end{array}$ & $\begin{array}{l}\text { HC mean } \\
\pm \mathrm{SD}\end{array}$ & \\
\hline WBC $\times 10^{3}$ cells $/ \mu \mathrm{l}$ & $8.35 \pm 3.3$ & $6.83 \pm 2.17$ & 0.007 & $8.62 \pm 2.89$ & $6.67 \pm 1.5$ & 0.001 \\
\hline AGC $\times 10^{3}$ cells $/ \mu \mathrm{l}$ & $5.62 \pm 2.97$ & $3.9 \pm 1.85$ & 0.001 & $5.65 \pm 2.67$ & $3.66 \pm 1.22$ & 0.001 \\
\hline ALC $\times 10^{3}$ cells $/ \mu 1$ & $1.90 \pm 0.52$ & $2.2 \pm 0.58$ & 0.008 & $2.07 \pm 0.81$ & $2.28 \pm 0.55$ & 0.101 \\
\hline $\mathrm{CD}_{4}$ cells $/ \mu \mathrm{l}$ & $650 \pm 224$ & $883 \pm 256$ & 0.001 & $793 \pm 332$ & $975 \pm 300$ & 0.002 \\
\hline $\mathrm{CD}_{8}$ cells $/ \mu \mathrm{l}$ & $612 \pm 266$ & $675 \pm 277$ & 0.256 & $640 \pm 290$ & $712 \pm 260$ & 0.217 \\
\hline $\mathrm{CD}_{4} / \mathrm{CD}_{8}$ ratio & $1.17 \pm 0.44$ & $1.41 \pm 0.46$ & 0.009 & $1.59 \pm 0.95$ & $1.44 \pm 0.43$ & 0.268 \\
\hline $\mathrm{RBC} \times 10^{6}$ cells $/ \mu \mathrm{l}$ & $4.95 \pm 1.58$ & $5.81 \pm 0.74$ & 0.001 & $4.74 \pm 0.99$ & $5.24 \pm 0.74$ & 0.001 \\
\hline $\mathrm{Hgb} \mathrm{g} / \mathrm{dl}$ & $13.3 \pm 4.6$ & $17.1 \pm 2.2$ & 0.001 & $12.5 \pm 3.6$ & $14.9 \pm 2.2$ & 0.001 \\
\hline MCV fl & $88.0 \pm 14$ & $94 \pm 5.8$ & 0.001 & $87 \pm 14.7$ & $93.2 \pm 7.2$ & 0.001 \\
\hline $\mathrm{MCHC} \mathrm{g} / \mathrm{dl}$ & $32.09 \pm 2.18$ & $33.34 \pm 0.82$ & 0.001 & $32 \pm 2.6$ & $33 \pm 0.8$ & 0.001 \\
\hline PLT $\times 10^{3}$ cells $/ \mu 1$ & $455.9 \pm 329$ & $315 \pm 124$ & 0.001 & $442 \pm 317$ & $340 \pm 144$ & 0.001 \\
\hline
\end{tabular}

$\mathrm{HC}=$ healthy controls

Further analysis using Post Hoc Tukey test showed that mean $\mathrm{CD}_{4}$ cells count of DTB group was significantly lower than TBL $(\mathrm{p}=0.034)$ and healthy control group $(\mathrm{p}<0.001)$ but showed no statistically significant difference with PTB (0.884). Mean $\mathrm{CD}_{4}$ cells count of PTB also lower than TBL $(\mathrm{p}=0.009)$ and healthy control group $(\mathrm{p}=0.001)$ (Fig. 1). Of the total $108 \mathrm{~TB}$ patients $24(22.2 \%)$ had low CD4 count $(<500$ cells $/ \mu 1)$, of whom $5(4.6 \%)$ had severe $\mathrm{CD}_{4}$ lymphocytopenia $(<300$ cells $/ \mu \mathrm{l})$.

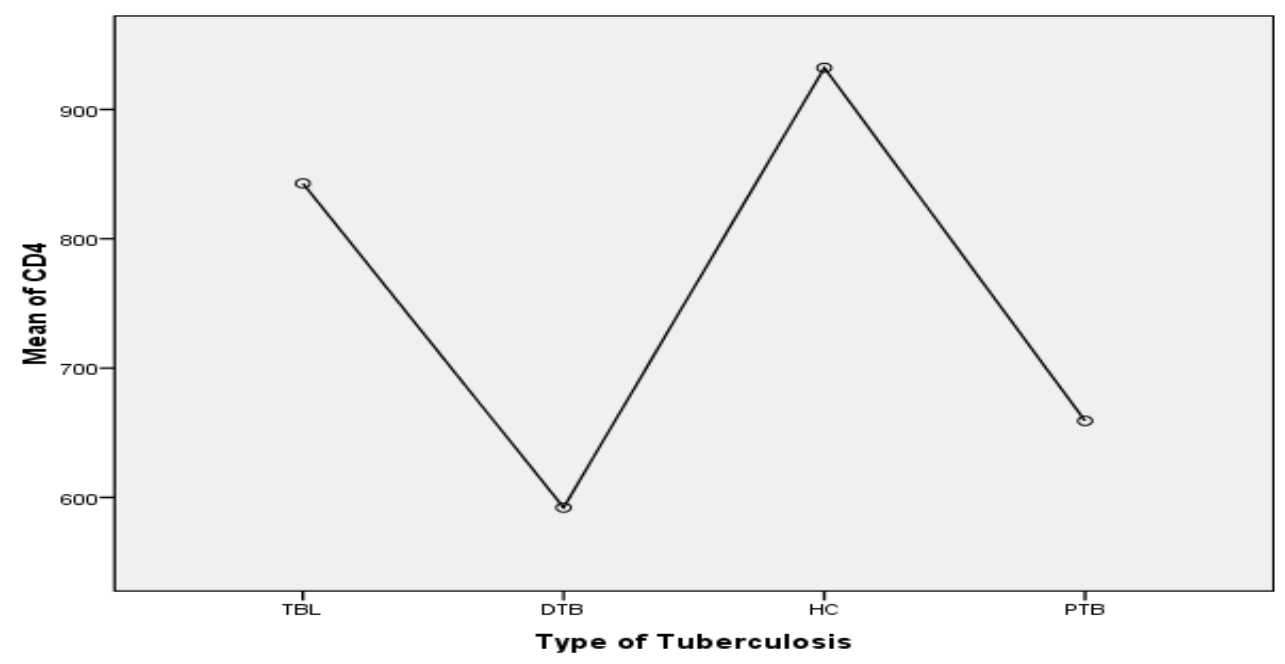

Figure 1: Comparson of mean $C_{4}$ count between different tuberculosis group; TBL (Tuberculoous lymphadnitis), DTB (Dissiminated TB), PTB (Pulmonary TB) and healthy control (HC) 
Mean \pm SD of RBC counts, haemoglobin (Hgb), $\mathrm{MCV}, \mathrm{MCH}$ and $\mathrm{MCHC}$ values of TB patients were significantly lower than those male and female healthy controls $(\mathrm{p}=0.001)$. Platelet counts and red cell distribution width (RDW) were significantly higher in both sexes among cases than controls $(\mathrm{p}=0.001)$ (Table 2). Further analysis by Post Hoc Tukey test showed mean Hgb values of all groups of TB patients were lower than those of control group ( $\mathrm{p}=0.001)$. Mean $\mathrm{Hgb}$ values of PTB group were also lower than TBL $(\mathrm{p}=0.028)$ and no statistical significant difference between PTB and DTB cases were observed $(p=0.941)$
(Fig. 2). From cases, 40(37.0\%) were found anaemic of whom $38(95.0 \%)$ had moderate anaemia and $2(5.0 \%)$ severe anaemia. From these 40 anaemic cases, $13(32.5 \%)$ were among TBL, $5(12.5 \%)$ among DTB and 22(55.0\%) among PTB. The RBC morphology and RBC indices in our study showed that $15(37.5 \%)$ of cases developed normocytic normochromic anaemia followed by normocytic hypochromic anaemia, 13(32.6\%), (Table 3). From a total of 53(49.1\%) thrombocytosis, PTB accounted for 26(49.1\%), TBL for 21(39.6\%) and DTB for 6(11.3\%).

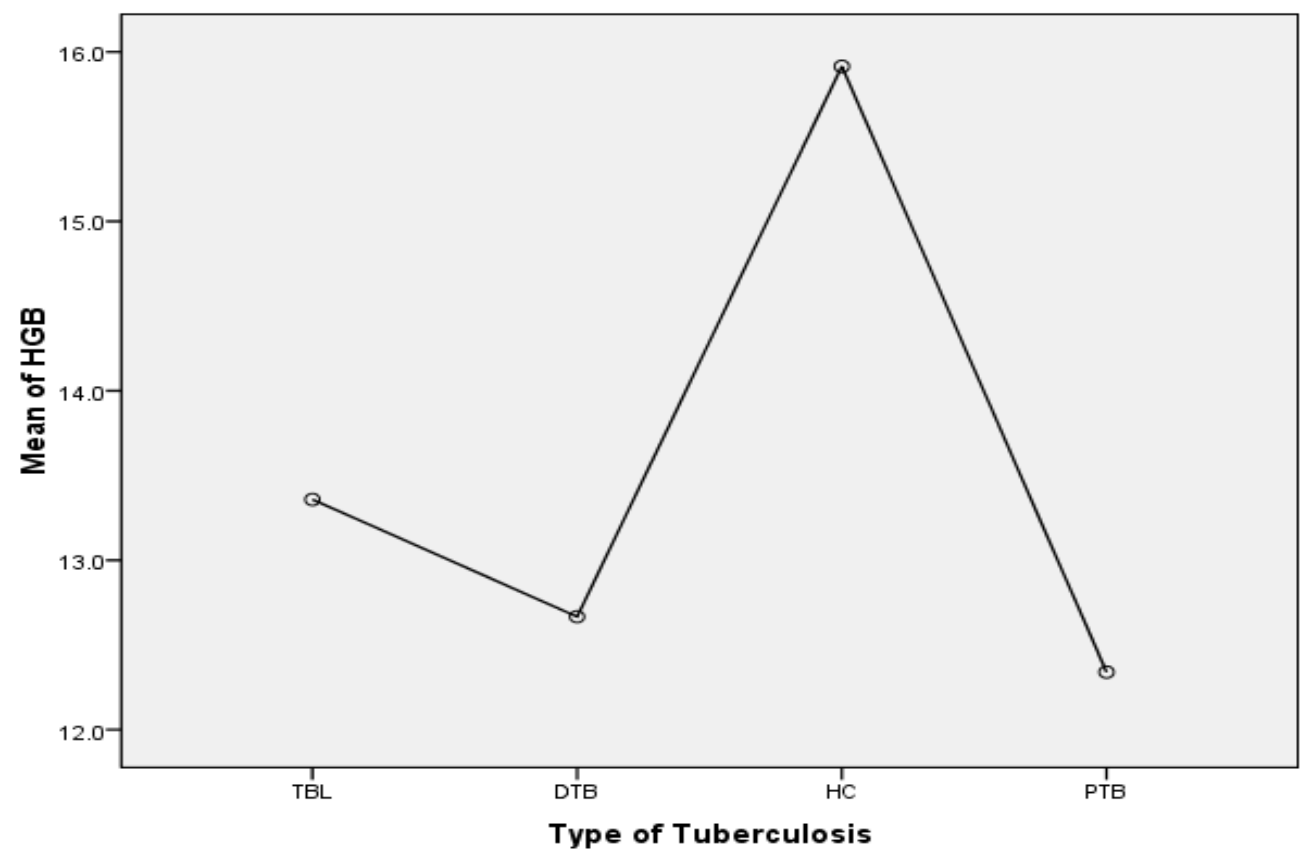

Figure. 2: Comparson of mean Hemoglobine (Hgb) value between diffirent tuberculosis group; TBL (Tuberculous lymphadnitis), DTB (Dissiminated TB) PTB (Pulmonary TB) and healthy control (HC)

Table 3: Classification of anemia, red cell morphology and indices among newly diagnosed TB patients

\begin{tabular}{lllll}
\hline & & \multicolumn{2}{c}{ MCHC(pg) } & Total \\
\cline { 2 - 5 } MCV (fl) & Microcytic & Hypochromic & Normochromic \\
& Normocytic & $13(20 \%)$ & $2(5 \%)$ & $10(25 \%)$ \\
& Macrocytic & $2(5 \%)$ & $15(37.5 \%)$ & $28(70 \%)$ \\
Total & & $23(57.5 \%)$ & 0 & $2(5 \%)$ \\
\hline
\end{tabular}

$\mathrm{MCV}=$ mean corpuscular volume, $\mathrm{fl}=$ femtoliter

\section{DISCUSSION}

M. tuberculosis has a variety of surface molecules that interact with the innate host response. The interaction of the bacterial surface molecules along with the auto-regulation of the immune response by several mechanisms results in less optimal conditions for control of bacterial growth 
(4). M. tuberculosis is a classic example of a pathogen for which the protective response relies on cell mediated immunity. . Both $\mathrm{CD}_{4}$ and $\mathrm{CD}_{8}$ T-cells are important for successful immunity to TB (8).

In our finding, the mean $\mathrm{CD}_{4}$ count of both male and female TB patients was significantly lower than that of the respective healthy control. Absolute $\mathrm{CD}_{8}$ count has no significant difference between TB patients and healthy controls in both sexes. $\mathrm{CD}_{4} / \mathrm{CD}_{8}$ ratio in male $\mathrm{TB}$ patients was decreased relative to male healthy controls but in female TB patients, there is no significant difference in $C D 4 / C D_{8}$ ratio with female healthy controls. The finding of our study is comparable to a study conducted in Pune, India, among 39 male patients who were HIV negative but PTB positive. The study showed that $\mathrm{CD}_{4}$ counts were significantly lower, $\mathrm{CD}_{8}$ values were normal in patients with PTB when compared with values obtained in normal blood donors. The $\mathrm{CD}_{4} / \mathrm{CD}_{8}$ ratio was significantly lower in patients with $\mathrm{TB}$ (9).

Another similar study conducted in Tan Tock Seng Hospital in Singapore on 60 patients showed that patients with TB had a lower median absolute lymphocyte count, lower $\mathrm{CD}_{8}$ count and a trend towards a lower $\mathrm{CD}_{4}$ count when compared to controls (10). A study done in Turkey on 75 active PTB patients has shown reduced percentage of circulating $\mathrm{CD}_{4} \mathrm{~T}$ cells and $\mathrm{CD}_{8} \mathrm{~T}$ cells compared with healthy individuals (11). A study from United States conducted on 85 HIV negative patients also reported comparable findings (12). The low mean $\mathrm{CD}_{4}$ count among TB patient than healthy controls in this study is also comparable with the finding of other studies $(5,10,12-16)$.

In our study, the $\mathrm{CD}_{4}$ count of $\mathrm{TB}$ patients is compared against the type of $\mathrm{TB}$. Lower $\mathrm{CD}_{4}$ count was recorded among cases of disseminated TB than tuberculous lymphadenitis but no significant difference was observed with PTB. Similar to study from Guangzhou Chest Hospital, China, our study revealed that $\mathrm{CD}_{4}$ count from patients of disseminated TB was lower than patients with PTB (16). But, a study done in Tehran showed that mean $\mathrm{CD}_{4}$ count of disseminated TB was lower than all other types of TB (15). In another study done on PTB in Turkey and in E. Tornu Hospital, Argentina, introduced that mean $\mathrm{CD}_{4}$ count significantly decreased in patients than control groups $(11,17)$. Similar with other previous studies $(9,17)$, the difference in mean $\mathrm{CD}_{8}$ count between the cases and control was not statistically significant in our finding.

Mean RBC counts, Hgb, MCV, MCH and $\mathrm{MCHC}$ values were significantly lower than the corresponding control group for both males and females. From 40(37\%) study subjects who developed anaemia, $15(32.6 \%)$ had normocytic normochromic anaemia followed by $13(32.5 \%)$ those who normocytic hypochromic anaemia. Other similar studies have reported lower haemoglobin levels among TB patients (13, 1821). However, study conducted on adult patients diagnosed with TB at Seoul National University Hospital, Korea among 880 patients, anaemia was identified in 281 patients $(31.9 \%)$ at the time of diagnosis [19] which was lower than the present study. It also showed that Normocytic normochromic anaemia was most common and identified in $202(71.9 \%)$ patients and followed by microcytic hypochromic anaemia 26(9.1\%) (19). On the other hand, a study conducted in India reported normocytic normochromic anaemia as the most common abnormality observed in all cases, groups and subgroups (DTB/MTB 84\%, PTB $86 \%$ ) (18). The variation might be due to the difference in the stage of the disease during diagnosis, geographic, nutrition and other cultural differences that may directly or indirectly be related to anaemia.

The platelet counts of newly diagnosed TB patients among PTB patients were higher as compared to healthy controls. A study conducted at India Institute of Medical Sciences, New Delhi, on 32 DTB and 23 PTB indicated that thrombocytopenia was more common in patients with disseminated/miliary TB, whereas thrombocytosis was more common in patients with PTB (18). A study in Sao Paulo State University, Brazil, on 80 PTB patients revealed that platelet count values were higher in those with less clinical disease duration (22). This was, because of the fact that, at the beginning of the TB process, there was strong pro-inflammatory cytokine activity (IFN- $\gamma$ \& TNF- $\alpha$ ) which stimulates expression of acute-phase proteins and thrombocytosis.

This study demonstrated that the mean $\mathrm{CD}_{4}$ count is significantly lower in newly diagnosed TB patients when compared with apparently 
healthy control for both male and female. The mean $\mathrm{CD}_{8}$ count is comparable among cases and control groups. Haematological parameters like $\mathrm{RBC}$ count, $\mathrm{Hgb}, \mathrm{MCV}$ and $\mathrm{MCHC}$ were significantly lower when compared with healthy controls. Morphologically normocytic normochromic anaemia is a common haematological abnormality among TB patients. Increased thrombocytosis was observed among newly diagnosed treatment naive TB patients.

Our study was not without pitfalls. First, apparently healthy controls were recruited depending only from the blood bank information. Second, due to logistic reasons, in-depth characterization of immune cells to appreciate their functional status was not performed.

\section{ACKNOWLEDGEMENTS}

This study was funded by Jimma University, Collage of Public Health and Medical Sciences Research Program. We acknowledge the support of the Jimma University Specialized Hospital Laboratory and TB Clinic workers. The authors are thankful to all the study participants for their trust and collaboration.

\section{REFERENCES}

1. WHO declares tuberculosis a global emergency. Sozial-und Präventivmedizin/ Social and Preventive Medicine, 1993; 38(4):251-252.

2. WHO, Global Tuberculosis Control. 2011.

3. MOH, Monthly HIV Care and ART Update. 2008: Addis Ababa, Ethiopia.

4. Kaufmann S.H, How can immunology contribute to the control of tuberculosis? Nat Rev Immunol, 2001; 1(1):20-30.

5. Al-Aska A, Al-Anazi AR, Al-Subaei SS, et al., CD4+ T-lymphopenia in HIV negative tuberculous patients at King Khalid University Hospital in Riyadh, Saudi Arabia. Eur J Med Res, 2011; 16 (6):285-8.

6. Zhu J., Y.H. and, and P.W. E., Differentiation of effector CD4 T cell populations. Annu Rev Immunol, 2010; 28: 445-89.

7. Flynn J. L. and C. J., Immunology of tuberculosis. Аnnu Rev Immunol, 2001; 19: 93-129.
8. Cooper A. M, Cell-mediated immune responses in tuberculosis. Annu Rev Immunol, 2009;27: 393-422.

9. Uppal SS, T.S., Verma S, and Dhot PS, Comparison of CD4 and CD8 Lymphocyte Counts in HIV-Negative Pulmonary TB Patients With Those in Normal Blood Donors and the Effect of Anti-tubercular Treatment: Hospital-Based Flow Cytometric Study. Cytometry Part B (Clinical Cytometry), 2004; 61B:20-26.

10. Villacian JS, T.G., Teo LF, Paton NI, The effect of infection with Mycobacterium tuberculosis on T-cell activation and proliferation in patients with and without HIV co-infection. J Infect, 2005. 51(5): 408-12. .

11. Deveci F, Akbulut H, Celik L et al., Lymphocyte subpopulations in pulmonary tuberculosis patients. Mediators Inflamm, 2006;2: 89070.

12. Jones B. E, Oo MM, Taikwel EK. et al., CD4 cell counts in human immunodeficiency virusnegative patients with tuberculosis. Clin Infect Dis, 1997; 24(5): 988-91.

13. Kony SJ, Hanne AA, Larouze B, et al., Tuberculosis-associated severe CD4+ Tlymphocytopenia in HIV-seronegative patients from Dakar. SIDAK Research Group. J Infect, 2000; 41(2): 167-71.

14. Pessaran Z., F.F., Oreizi F., Ghavaminejad A., Kiani A. and Siadat ZD. Immunophenotypic Characterization of Peripheral Blood TLymphocytes and Their Subpopulations in Tuberculosis Patients before and after Treatments. Iran J Allergy Asthma Immunol. 2005; 4(1): 23-6.

15. Davoudi S, Rasoolinegad M, Younesian M. et al., CD4+ cell counts in patients with different clinical manifestations of tuberculosis. Braz $J$ Infect Dis, 2008; 12(6): 483-6.

16. Li D. X, Zhang TT, Tan SY. et al., The clinical significance of changes in CD4+ T cell counts by peripheral blood from patients with pulmonary tuberculosis after antitubercular treatment. Xi Bao Yu Fen $\mathrm{Zi}$ Mian Yi Xue Za Zhi, 2010;26(7): 679-81.

17. Pilheu JA, De Salvo MC, Gonzalez J. et al., CD4+ T-lymphocytopenia in severe pulmonary tuberculosis without evidence of human immunodeficiency virus infection. Int J Tuberc Lung Dis, 1997;1(5):422-6. 
18. Singh KJ, A.G., Sharma SK, Saxena R, Chaudhary VP, Anant M., Significance of haematological manifestations in patients with tuberculosis. J Assoc Physicians India, 2001; 49(788): 790-4.

19. Lee SW, Kang YA, Yoon YS et al., The prevalence and evolution of anemia associated with tuberculosis. J Korean Med Sci, 2006; 21(6): 1028-32.

20. Al-Omar I.A., A.-A.R.M., and Shah A.H., Hematological abnormalities in Saudis suffering from pulmonary tuberculosis and their response to the treatment. Research Journal of Pharmacology, 2009; 3(4): 78-85.

21. Saathoff E., V.E., Mugusi F., Bosch RJ. Urassa W., and Fawzi WW. Anemia in adults with tuberculosis is associated with HIV and anthropometric status in Dar es Salaam, Tanzania. International Journal of Tuberculosis and Lung Disease 2011;15(7): 925-932.

22. Oliva V. M, Cezario G.A.G, Cocato R.A, Marchondes-Machado J et al., Pulmonary tuberculosis: hematology, serum biochemistry and the relation with the disease duration. Journal of Venomous Animals and Toxins including Tropical Diseases, 2008; 14: 71-81. 